\title{
Fruit and vegetable consumption in a sample of 11 -year-old children in ten European countries - the PRO GREENS cross-sectional survey
}

Christel Lynch ${ }^{1, *}$, Asa Gudrun Kristjansdottir ${ }^{2}$, Saskia J te Velde ${ }^{3}$, Nanna Lien ${ }^{4}$, Eva Roos ${ }^{5,6}$, Inga Thorsdottir ${ }^{2}$, Michael Krawinkel ${ }^{7}$, Maria Daniel Vaz de Almeida ${ }^{8}$, Angeliki Papadaki ${ }^{9,10}$, Cirila Hlastan Ribic ${ }^{11}$, Stefka Petrova ${ }^{12}$, Bettina Ehrenblad ${ }^{1}$, Thorhallur I Halldorsson ${ }^{2}$, Eric Poortvliet ${ }^{1}$ and Agneta Yngve ${ }^{1,13}$

'Department of Biosciences and Nutrition, Karolinska Institutet, NOVUM, SE 14183 Huddinge, Stockholm, Sweden: ${ }^{2}$ Unit for Nutrition Research, Faculty of Food Science and Nutrition, School of Health Sciences, University of Iceland \& Landspitali University Hospital, Reykjavik, Iceland: ${ }^{3}$ EMGO Institute for Health and Care Research and Department of Epidemiology \& Biostatistics, VU University Medical Center, Amsterdam, The Netherlands: ${ }^{4}$ Department of Nutrition, Faculty of Medicine, University of Oslo, Oslo, Norway: ${ }^{5}$ Folkhälsan Research Center, Helsinki, Finland: ${ }^{6} \mathrm{Hjelt}$ Institute, Department of Public Health, University of Helsinki, Helsinki, Finland: ${ }^{7}$ Institute of Nutritional Sciences, Unit for International Nutrition, Faculty of Agricultural Nutrition, Environmental Sciences and Home Economics, Justus-Liebig University, Giessen, Germany: ${ }^{8}$ Faculty of Nutrition and Food Sciences, University of Porto, Porto, Portugal: ${ }^{9}$ Department of Social Medicine, Preventive Medicine and Nutrition Clinic, University of Crete, Heraklion, Crete, Greece: ${ }^{10} \mathrm{Centre}$ for Exercise, Nutrition and Health Sciences, School for Policy Studies, University of Bristol, Bristol, UK: ${ }^{11}$ National Institute of Public Health, Ljubliana, Slovenia: ${ }^{12}$ National Center for Public Health Protection, Sofia, Bulgaria: ${ }^{13}$ School of Hospitality, Culinary Arts and Meal Sciences, Örebro University, Örebro, Sweden

Submitted 18 March 2013: Final revision received 13 May 2014: Accepted 25 May 2014: First published online 15 July 2014

\begin{abstract}
Objective: To describe fruit and vegetable intake of 11-year-old children in ten European countries and compare it with current dietary guidelines.

Design: Cross-sectional survey. Intake was assessed using a previously validated questionnaire containing a pre-coded $24 \mathrm{~h}$ recall and an FFQ which were completed in the classroom. Portion sizes were calculated using a standardized protocol.

Setting: Surveys were performed in schools regionally selected in eight countries and nationally representative in two countries.

Subjects: A total of 8158 children from 236 schools across Europe participating in the PRO GREENS project.

Results: The total mean consumption of fruit and vegetables was between 220 and $345 \mathrm{~g} / \mathrm{d}$ in the ten participating countries. Mean intakes did not reach the WHO population goal of $\geq 400 \mathrm{~g} / \mathrm{d}$ in any of the participating countries. Girls had a significantly higher intake of total fruit and vegetables than boys in five of the countries (Sweden, Finland, Iceland, Bulgaria and Slovenia). Mean total fruit intake ranged between 114 and $240 \mathrm{~g} / \mathrm{d}$ and vegetable intake between 73 and $141 \mathrm{~g} / \mathrm{d}$. When using the level $\geq 400 \mathrm{~g} / \mathrm{d}$ as a cut-off, only $23.5 \%$ (13.8-37.0\%) of the studied children, depending on country and gender, met the WHO recommendation (fruit juice excluded).

Conclusions: Fruit and vegetable consumption was below recommended levels among the schoolchildren in all countries and vegetable intake was lower than fruit intake. The survey shows that there is a need for promotional activities to improve fruit and vegetable consumption in this age group.
\end{abstract}

It has been recognized for some time that fruit and vegetables (F\&V) constitute an essential part of a healthy $\operatorname{diet}^{(1-3)}$. High consumption of $F \& V$ has been associated with a decreased risk of morbidity and mortality from a number of chronic diseases like $\mathrm{CHD}^{(4)}$, stroke ${ }^{(5)}$, type 2 diabetes $^{(6)}$ and certain cancers ${ }^{(7)}$. F\&V are low in energy 
but contain high amounts of essential nutrients, phytochemicals, dietary fibre and other bioactive compounds that have health-promoting properties ${ }^{(8)}$.

The WHO recommends eating a minimum of $400 \mathrm{~g}$ of F\&V per day ${ }^{(9)}$, but few children in Europe seem to reach this target according to the previous Pro Children survey ${ }^{(10)}$ performed in nine European countries in 2003. The 2007 report of the World Cancer Research Fund/ American Institute for Cancer Research also proposed an individual consumption of non-starchy vegetables and fruits of over $400 \mathrm{~g} / \mathrm{d}^{(3)}$. National food-based dietary guidelines for $\mathrm{F} \& \mathrm{~V}$ intake can be found in all participating countries $^{(11-20)}$ and most of them are higher than the WHO or World Cancer Research Fund/American Institute for Cancer Research recommendations. The different country recommendations are, however, very diverse and use different approaches to formulating dietary guidelines.

Food habits early in life tend to track to a certain extent into adulthood ${ }^{(21-23)}$, which is why it is important to promote F\&V consumption among children and adolescents. Therefore, several school-based or family-based initiatives have been implemented in order to promote $\mathrm{F} \& \mathrm{~V}$ intake among schoolchildren ${ }^{(24-28)}$. These programmes had a positive effect on actual intake levels among this target group in the countries where they were implemented. In order to build further on these programmes and strategies, we need to re-assess the current intake levels among this age group and also disseminate and implement the research tools in other countries in Europe.

The PRO GREENS project was designed to assess actual levels of fruit intake and vegetable intake among 11-year-old schoolchildren in ten European countries (Bulgaria, Finland, Germany, Greece, Iceland, Norway, Portugal, Slovenia, Sweden and the Netherlands). The age group 11-year-olds was chosen since it is a critical time point before adolescence and because it is an age group that is able to complete a questionnaire with some rigour $^{(29)}$. In addition, the age group made it possible to intervene and follow-up in the schools while minimizing the risk of children changing schools before the end of the intervention. The aims also included to further investigate the determinants of intake and to develop and test feasible, effective and sustainable strategies to promote $\mathrm{F} \& \mathrm{~V}$ consumption among schoolchildren. The project builds on methods and results from the Pro Children survey, the first ever cross-national comparison of $\mathrm{F} \& \mathrm{~V}$ intake performed in children in Europe ${ }^{(30)}$. In PRO GREENS, five countries that participated in the previous Pro Children survey and five additional countries, including three new EU member states (Bulgaria, Greece and Slovenia), teamed up to provide new information about the F\&V intake levels of schoolchildren in Europe and to spread the use of the validated methodology of assessment of F\&V intake. So far, little is known about the consumption of $F \& V$ in children in the new member states.
The aim of the current paper was to present the findings from the PRO GREENS baseline survey with regard to the current consumption levels of fruit and of vegetables in a sample of 11-year-old children in ten countries in Europe and compare the results with the current WHO recommendations.

\section{Methods}

\section{Sampling}

The baseline cross-sectional survey was performed during April to October 2009 in the ten countries (Bulgaria, Finland, Germany, Greece, Iceland, Norway, Portugal, Slovenia, Sweden and the Netherlands). Sampling of schools was performed regionally in all countries except in Slovenia and the Netherlands, where the samples were nationally representative. In Bulgaria, Finland, Iceland, Norway and Sweden, schools were selected in the capital regions or in restricted areas. In Finland, only Swedishspeaking schools were included. In Germany, Greece and Portugal, the selection of schools was made in close vicinity to the research centres (Porto, Heraklion and Giessen). The total sample is not representative for the whole of Europe.

From each country, an original sample selection of at least 1000 children was included. The sample was considered large enough not only for the survey reported here but also to serve as the baseline measurement of the subsequent intervention study. For this latter study, the sample will be randomly assigned to an intervention and control group (at the school level). The number of children was sufficient to detect a difference in consumption between the intervention and control group of $20 \mathrm{~g} / \mathrm{d}$ given a mean intake of $200 \mathrm{~g} / \mathrm{d}$, a standard deviation of $175 \mathrm{~g} / \mathrm{d}$ and $\alpha$ error level of $5 \%$ to reach a power of $80 \%$.

\section{Ethical considerations}

Self-administered questionnaires were the only research instrument used and participation was voluntary. All participating research centres obtained ethical approval from local or national research ethics committees before conducting the survey. Parental consent was in some countries retrieved prior to including the children in the crosssectional survey, in other countries afterwards. Parents were either contacted directly by mail if home addresses had been provided by the school, or reached through the class teacher. In Norway, data safety authorities were involved, in accordance with national regulations.

\section{Instrument}

The validated Pro Children questionnaire ${ }^{(29)}$ was modified slightly, translated if needed into each local language and used for assessing the F\&V intake in all countries. Berries were added and some small adjustments were made to the lunch meal question in order to better capture lunch eaten 
in school as well as lunch eaten at home and to make it fit circumstances around the lunch meal in all participating countries better. The questionnaire constitutes a precoded $24 \mathrm{~h}$ recall component with detailed questions regarding yesterday's intake of fruit and of vegetables and a food-frequency component with questions about usual F\&V intake. Quantities in grams per day were estimated according to a protocol described elsewhere ${ }^{(29)}$. The children completed the questionnaire in the classroom with help from the teacher or research staff. Vegetable intake was divided into four categories; raw, salad, cooked and soup vegetables. Raw vegetables included whole, cutup or sliced vegetables like carrot sticks, tomatoes, slices of bell pepper, cucumber, etc. served separately (not as part of a salad). Salad vegetables included mixed uncooked vegetables, sliced, grated or chopped. Cooked vegetables included boiled, fried or baked vegetables. One portion of vegetable soup ( $250 \mathrm{~g}$ was considered to include $80 \mathrm{~g}$ of soup vegetables.

\section{Data bandling}

A data management handbook was developed, based on the Pro Children data management handbook ${ }^{(28)}$. A child was regarded as a non-participant if he/she had completely misunderstood the questionnaire. The $24 \mathrm{~h}$ recalls were defined as incomplete if more than three out of ten answers were missing on questions regarding fruit, raw vegetables, salad or cooked vegetables (e.g. 'Did you eat fruit yesterday before school?' yes/no; Table 1). If three or fewer answers were missing the intake was coded as 0 for the missing answers. Missing values on individual questions were in most cases low $(<2 \%)$ although in one case (Germany) the number of missing values was in some cases as high as $8 \%$.

Maximum portions were set for 'berries' and 'other fruits' as children sometimes misunderstood how to report the amount of these food items; reported intake above three portions was set to a maximum intake of three portions. Outliers, less than $1 \%$ of participants, had a calculated intake corresponding to more than $1200 \mathrm{~g} \mathrm{~F} \& \mathrm{~V} / \mathrm{d}$.
Fruit juice was not included in the analysis since it was shown in focus groups that children have difficulties distinguishing fruit juice from other fruit-based and -flavoured beverages $^{(31)}$. Potatoes, dried fruit, nuts and canned fruit were not included. We did not ask about vegetables included in composite dishes (e.g. carrot cake), except for vegetable soup and salads.

\section{Statistical analysis}

Data analysis was performed using the statistical software package IBM SPSS Statistics 20·0. Methods for calculating portions and amounts have been described in more detail elsewhere ${ }^{(29)}$. The statistical significance for differences in intake between boys and girls was set as $P<0 \cdot 05$. Data from the $24 \mathrm{~h}$ recall showed a large skewed distribution due to the large number of zeros (child did not eat fruit or vegetables on the day of data collection). Therefore, the non-parametric Mann-Whitney $U$ test was used to compare intakes between girls and boys. The Kruskal-Wallis test was used to compare intake across countries. Next, post boc pair-wise multiple comparisons (non-parametric) were performed for which adjusted $P$ values were calculated in order to control the type I error $\left(P_{\mathrm{adj}}=P K(K-1) / 2\right)$. Proportions of children meeting the recommendations were compared across countries using the $\chi^{2}$ test and multiple pair-wise comparisons, adjusted with the Bonferroni correction.

When analysing data for the whole sample all children were included; however, for analysis on girls and boys separately, three children were excluded since only the children with known gender could be included.

\section{Results}

\section{Participation rates}

A total of 8158 children were included in the final database. One hundred and sixty-one questionnaires were excluded from the analysis due to exclusion criteria

Table 1 Sample selection, response rates and data cleaning description by country for 236 schools across ten European countries participating in the PRO GREENS project, April-October 2009

\begin{tabular}{|c|c|c|c|c|c|c|c|c|c|c|}
\hline \multirow[b]{2}{*}{ Country } & \multirow{2}{*}{$\begin{array}{c}\text { Sampled } \\
\text { schools }\end{array}$} & \multirow{2}{*}{$\begin{array}{c}\begin{array}{c}\text { Participating } \\
\text { schools }\end{array} \\
n\end{array}$} & \multirow{2}{*}{$\begin{array}{c}\text { Eligible } \\
\text { sample }\end{array}$} & \multicolumn{2}{|c|}{ Response rate } & \multicolumn{2}{|c|}{ Data entry } & \multicolumn{3}{|c|}{ Data included in the analysis } \\
\hline & & & & $n$ & $\%$ of part & $n$ & $\%$ of part & $n$ & $\%$ of part & $\%$ of data entry \\
\hline Bulgaria & 12 & 12 & 1174 & 1091 & 92.9 & 985 & 83.9 & 963 & $82 \cdot 0$ & $97 \cdot 8$ \\
\hline Finland & 19 & 19 & 1123 & 1071 & 95.4 & 950 & 84.6 & 934 & $83 \cdot 2$ & $98 \cdot 3$ \\
\hline Germany & 45 & 14 & 1300 & 816 & $62 \cdot 8$ & 803 & $61 \cdot 8$ & 784 & $60 \cdot 3$ & $97 \cdot 6$ \\
\hline Greece & 53 & 40 & 972 & 920 & 94.7 & 905 & $93 \cdot 1$ & 892 & $91 \cdot 8$ & 98.6 \\
\hline Iceland & 24 & 19 & 1036 & 805 & $77 \cdot 7$ & 720 & 69.5 & 702 & $67 \cdot 8$ & 97.5 \\
\hline Norway & 104 & 15 & 934 & 590 & $63 \cdot 2$ & 505 & $54 \cdot 1$ & 479 & $51 \cdot 3$ & 94.9 \\
\hline Portugal & 5 & 5 & 979 & 931 & $95 \cdot 1$ & 898 & 91.7 & 883 & $90 \cdot 2$ & $98 \cdot 3$ \\
\hline Slovenia & 44 & 33 & 1509 & 1392 & $92 \cdot 2$ & 1233 & $81 \cdot 7$ & 1218 & $80 \cdot 7$ & $98 \cdot 8$ \\
\hline Sweden & 86 & 26 & 1234 & 737 & $59 \cdot 7$ & 737 & $59 \cdot 7$ & 726 & $58 \cdot 8$ & 98.5 \\
\hline The Netherlands & 414 & 53 & 1046 & 589 & $56 \cdot 3$ & 584 & $55 \cdot 8$ & 577 & $55 \cdot 2$ & $98 \cdot 8$ \\
\hline TOTAL & 806 & 236 & 11307 & 8942 & $79 \cdot 1$ & 8320 & $73 \cdot 6$ & 8158 & $72 \cdot 2$ & $98 \cdot 1$ \\
\hline
\end{tabular}


described above (Table 1). The mean age of the participating children was 11.3 (SD 0.5) years.

\section{Twenty-four-hour recall}

Intake of total F\&V, intake of fruit and intake of vegetables separately from the $24 \mathrm{~h}$ recall are presented in Table 2 . The mean intake of total F\&V ranged between 220 and
$345 \mathrm{~g} / \mathrm{d}$ in the ten participating countries. Girls had a significantly higher intake of total F\&V than boys in five of the countries (Bulgaria, Finland, Iceland, Slovenia and Sweden). The highest mean of total F\&V intake was found in Norway and Bulgaria (345 and $320 \mathrm{~g} / \mathrm{d}$, respectively) who had a significantly higher intake than all the other countries except for Sweden (291 g/d). The countries with

Table 2 Total fruit and vegetable (F\&V) intake, fruit intake and vegetable intake among 11-year-old children ( $n$ 8158) from 236 schools across ten European countries participating in the PRO GREENS project, April-October 2009. Results based on the $24 \mathrm{~h}$ recall in $\mathrm{g} / \mathrm{d}$, showing mean, standard deviation, median, 25th percentile (P25) and 75th percentile (P75) values. $P$ values are shown for gender differences

\begin{tabular}{|c|c|c|c|c|c|c|c|c|c|c|c|c|}
\hline \multirow[b]{2}{*}{ Country } & \multirow[b]{2}{*}{$n$} & \multicolumn{5}{|c|}{ Total F\&V intake $(\mathrm{g} / \mathrm{d})$} & \multirow[b]{2}{*}{ Pair-wise comparisons ${ }^{\star}$} & \multicolumn{2}{|c|}{ Girls } & \multicolumn{2}{|c|}{ Boys } & \multirow[b]{2}{*}{$P$ value } \\
\hline & & Mean & SD & Median & P25 & P75 & & Mean & Median & Mean & Median & \\
\hline \multicolumn{13}{|c|}{ a) Total F\&V intake } \\
\hline Bulgaria & 963 & 320 & 264 & 280 & 105 & 460 & a & 337 & 300 & 300 & 220 & 0.001 \\
\hline Finland & 934 & 220 & 199 & 170 & 80 & 300 & $\mathrm{e}$ & 231 & 190 & 209 & 150 & 0.005 \\
\hline Germany & 784 & 267 & 263 & 200 & 80 & 380 & $\mathrm{c}, \mathrm{d}, \mathrm{e}$ & 269 & 200 & 264 & 190 & 0.215 \\
\hline Greece & 892 & 280 & 258 & 210 & 90 & 400 & $b, c$ & 270 & 200 & 290 & 230 & 0.213 \\
\hline Iceland & 702 & 231 & 212 & 180 & 80 & 340 & d,e & 254 & 200 & 206 & 150 & 0.001 \\
\hline Norway & 479 & 345 & 290 & 280 & 100 & 515 & $a$ & 349 & 300 & 344 & 265 & 0.477 \\
\hline Portugal & 883 & 249 & 196 & 210 & 100 & 360 & $c, d$ & 253 & 208 & 246 & 210 & 0.580 \\
\hline Slovenia & 1218 & 226 & 213 & 180 & 80 & 320 & $\mathrm{e}$ & 242 & 200 & 208 & 160 & 0.002 \\
\hline Sweden & 726 & 291 & 233 & 248 & 114 & 410 & $a, b$ & 319 & 275 & 262 & 225 & 0.000 \\
\hline The Netherlands & 577 & 242 & 258 & 200 & 100 & 320 & $\mathrm{c}, \mathrm{d}, \mathrm{e}$ & 245 & 200 & 239 & 180 & 0.196 \\
\hline TOTAL & 8158 & 263 & 237 & 200 & 100 & 375 & $P<0.001 \dagger$ & 274 & 220 & 252 & 200 & $<0.001$ \\
\hline & & \multicolumn{5}{|c|}{ Fruit intake $(\mathrm{g} / \mathrm{d})$} & & \multicolumn{2}{|c|}{ Girls } & \multicolumn{2}{|c|}{ Boys } & \\
\hline Country & $n$ & Mean & SD & Median & P25 & P75 & Pair-wise comparison $\ddagger$ & Mean & Median & Mean & Median & $P$ value \\
\hline \multicolumn{13}{|l|}{ b) Fruit intake } \\
\hline Bulgaria & 963 & 197 & 202 & 150 & 0 & 300 & b & 204 & 200 & 189 & 100 & 0.019 \\
\hline Finland & 934 & 114 & 138 & 100 & 0 & 200 & e & 120 & 100 & 107 & 100 & 0.034 \\
\hline Germany & 784 & 168 & 190 & 100 & 0 & 200 & $c, d$ & 164 & 100 & 172 & 100 & 0.871 \\
\hline Greece & 892 & 178 & 186 & 100 & 0 & 250 & $b, c$ & 170 & 100 & 186 & 150 & 0.130 \\
\hline Iceland & 702 & 137 & 132 & 100 & 0 & 200 & $c, d$ & 171 & 100 & 139 & 100 & 0.002 \\
\hline Norway & 479 & 240 & 223 & 200 & 50 & 400 & $\mathrm{a}$ & 240 & 200 & 240 & 200 & 0.957 \\
\hline Portugal & 883 & 137 & 132 & 100 & 0 & 200 & d & 137 & 100 & 136 & 100 & 0.747 \\
\hline Slovenia & 1218 & 152 & 164 & 100 & 0 & 200 & $c, d$ & 160 & 100 & 143 & 100 & 0.016 \\
\hline Sweden & 726 & 150 & 155 & 100 & 0 & 200 & $b, c, d$ & 162 & 100 & 138 & 100 & 0.003 \\
\hline The Netherlands & 577 & 159 & 174 & 100 & 0 & 200 & $c, d$ & 159 & 100 & 159 & 100 & 0.783 \\
\hline TOTAL & 8158 & 161 & 175 & 100 & 0 & 200 & $P<0.001 \dagger$ & 166 & 100 & 157 & 100 & $<0.001$ \\
\hline & & \multicolumn{5}{|c|}{ Vegetable intake $(\mathrm{g} / \mathrm{d})$} & & \multicolumn{2}{|c|}{ Girls } & \multicolumn{2}{|c|}{ Boys } & \\
\hline Country & $n$ & Mean & SD & Median & P25 & P75 & Pair-wise comparisons§ & Mean & Median & Mean & Median & $P$ value \\
\hline \multicolumn{13}{|l|}{ c) Vegetable intake } \\
\hline Bulgaria & 963 & 123 & 122 & 90 & 40 & 180 & $a, b$ & 133 & 100 & 111 & 80 & 0.000 \\
\hline Finland & 934 & 106 & 114 & 80 & 29 & 145 & $\mathrm{~b}$ & 111 & 80 & 102 & 80 & 0.062 \\
\hline Germany & 784 & 99 & 135 & 50 & 0 & 140 & $c, d$ & 105 & 60 & 93 & 40 & 0.034 \\
\hline Greece & 892 & 101 & 131 & 60 & 0 & 140 & $c$ & 99 & 60 & 104 & 60 & 0.819 \\
\hline Iceland & 702 & 75 & 106 & 40 & 0 & 105 & $d$ & 83 & 50 & 67 & 40 & 0.003 \\
\hline Norway & 479 & 105 & 145 & 50 & 0 & 158 & $c, d$ & 107 & 50 & 103 & 58 & 0.586 \\
\hline Portugal & 883 & 112 & 106 & 80 & 16 & 160 & $a, b$ & 116 & 80 & 110 & 80 & 0.237 \\
\hline Slovenia & 1218 & 73 & 91 & 40 & 0 & 105 & $\mathrm{~d}$ & 82 & 40 & 65 & 40 & 0.000 \\
\hline Sweden & 726 & 141 & 148 & 100 & 40 & 190 & $\mathrm{a}$ & 157 & 120 & 124 & 80 & 0.000 \\
\hline The Netherlands & 577 & 83 & 108 & 60 & 0 & 120 & $c, d$ & 85 & 60 & 80 & 60 & 0.010 \\
\hline TOTAL & 8158 & 101 & 121 & 65 & 0 & 145 & $P>0.001 \dagger$ & 107 & 80 & 95 & 60 & $<0.001$ \\
\hline
\end{tabular}

${ }^{*}$ Pair-wise comparisons, adjusted significance levels. Countries for which intake levels are significantly different are denoted with different letters a-e (e.g. total F\&V intake in Bulgaria differs from intake in Finland, but not from intake in Norway and Sweden).

†Result from the non-parametric Kruskal-Wallis test.

‡Pair-wise comparisons, adjusted significance levels. Countries for which intake levels are significantly different are denoted with different letters a-e (e.g. fruit intake in Bulgaria differs from intake in Finland, but not from intake in Greece and Sweden).

$\S$ Pair-wise comparisons, adjusted significance levels. Countries for which intake levels are significantly different are denoted with different letters a-e (e.g. vegetable intake in Bulgaria differs from intake in Germany, but not from intake in Finland, Portugal and Sweden). 
the lowest total F\&V intake were Iceland, Slovenia and Finland (231, 226 and $220 \mathrm{~g} / \mathrm{d}$, respectively). The children in Sweden had the highest vegetable intake $(141 \mathrm{~g} / \mathrm{d})$, while children in Norway had the highest fruit intake $(240 \mathrm{~g} / \mathrm{d})$. Compared with boys, girls had a significantly higher intake of total F\&V as well as of fruit separately in Bulgaria, Finland, Iceland, Slovenia and Sweden, and a significantly higher vegetable intake in Bulgaria, Germany, Iceland, Slovenia, Sweden and the Netherlands.

The vegetable intake proportional by preparation method is shown in Fig. 1. There was a large variation in the types of vegetables consumed when comparing the Nordic countries with e.g. Portugal and Bulgaria. The two countries that differed most from the rest were Portugal and Sweden. Compared with any other country, Swedish children consumed proportionally more raw vegetables. Slovenia and Portugal had proportionally the lowest intake of raw vegetables and significantly lower than all countries except the Netherlands. Children in Portugal consumed proportionally more soup vegetables compared with all the other countries, followed by Slovenia that had a significantly higher intake of soup vegetables than all countries except Portugal, the Netherlands and Germany.

The mean consumption of total $\mathrm{F} \& \mathrm{~V}$ was below the WHO recommended amounts in all countries included. When the WHO recommendation of $\geq 400 \mathrm{~g} / \mathrm{d}$ was used as a cut-off for intake, the percentage of children who reached this target was $13 \cdot 8-37 \cdot 0 \%$ depending on country and gender, and $23.5 \%$ of the whole sample (Table 3 ).

\section{FFQ}

Reported frequencies of fruit and vegetable intakes are presented separately in Fig. 2. There is a large variation between countries in how many children report eating

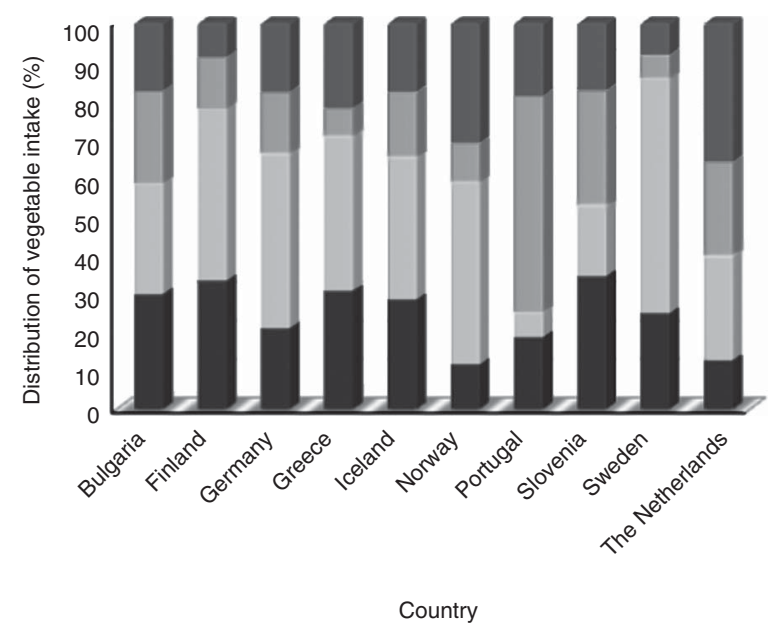

Fig. 1 Mean distribution (\%) of vegetable intake by preparation method and type ( $\square$, cooked vegetables; $\square$, soup vegetables; - , raw vegetables; $\square$, salad vegetables) per country ( $24 \mathrm{~h}$ recall) among 11-year-old children ( $n$ 8158) from 236 schools across ten European countries participating in the PRO GREENS project, April-October 2009
Table 3 Percentage with total fruit and vegetable (F\&V) intake $\geq 400 \mathrm{~g} / \mathrm{d}$ by gender and country among 11-year-old children ( $n$ 8158) from 236 schools across ten European countries participating in the PRO GREENS project, April-October 2009

\begin{tabular}{|c|c|c|c|c|}
\hline \multirow[b]{2}{*}{ Country } & \multicolumn{2}{|c|}{ Total F\&V intake $\geq 400 \mathrm{~g} / \mathrm{d}$} & \multirow{2}{*}{$\frac{\text { Girls }}{\%}$} & \multirow{2}{*}{$\frac{\text { Boys }}{\%}$} \\
\hline & $\%$ & Pair-wise comparisons ${ }^{*}$ & & \\
\hline Bulgaria & $31 \cdot 7$ & $a, b$ & 33.7 & $29 \cdot 3$ \\
\hline Finland & 13.8 & d & 14.4 & $13 \cdot 2$ \\
\hline Germany & 23.9 & c & $23 \cdot 6$ & $24 \cdot 2$ \\
\hline Greece & $26 \cdot 0$ & c & 23.3 & 28.8 \\
\hline Iceland & 19.5 & $c, d$ & $22 \cdot 2$ & $16 \cdot 7$ \\
\hline Norway & $37 \cdot 0$ & $\mathrm{a}$ & 38.2 & $35 \cdot 6$ \\
\hline Portugal & $21 \cdot 0$ & c & $22 \cdot 3$ & $19 \cdot 7$ \\
\hline Slovenia & $16 \cdot 8$ & $d$ & $17 \cdot 9$ & $15 \cdot 7$ \\
\hline Sweden & $26 \cdot 0$ & $b, c$ & 31.0 & $21 \cdot 1$ \\
\hline The Netherlands & $19 \cdot 1$ & $c, d$ & 21.0 & $17 \cdot 0$ \\
\hline TOTAL & 23.5 & & $24 \cdot 8$ & $22 \cdot 1$ \\
\hline
\end{tabular}

*Pair-wise comparisons with Bonferroni correction. Countries for which percentages meeting the recommendation are significantly different are denoted with different letters a-e (e.g. percentage meeting the recommendation in Bulgaria differs from that in Finland, but not from that in Norway and Sweden).
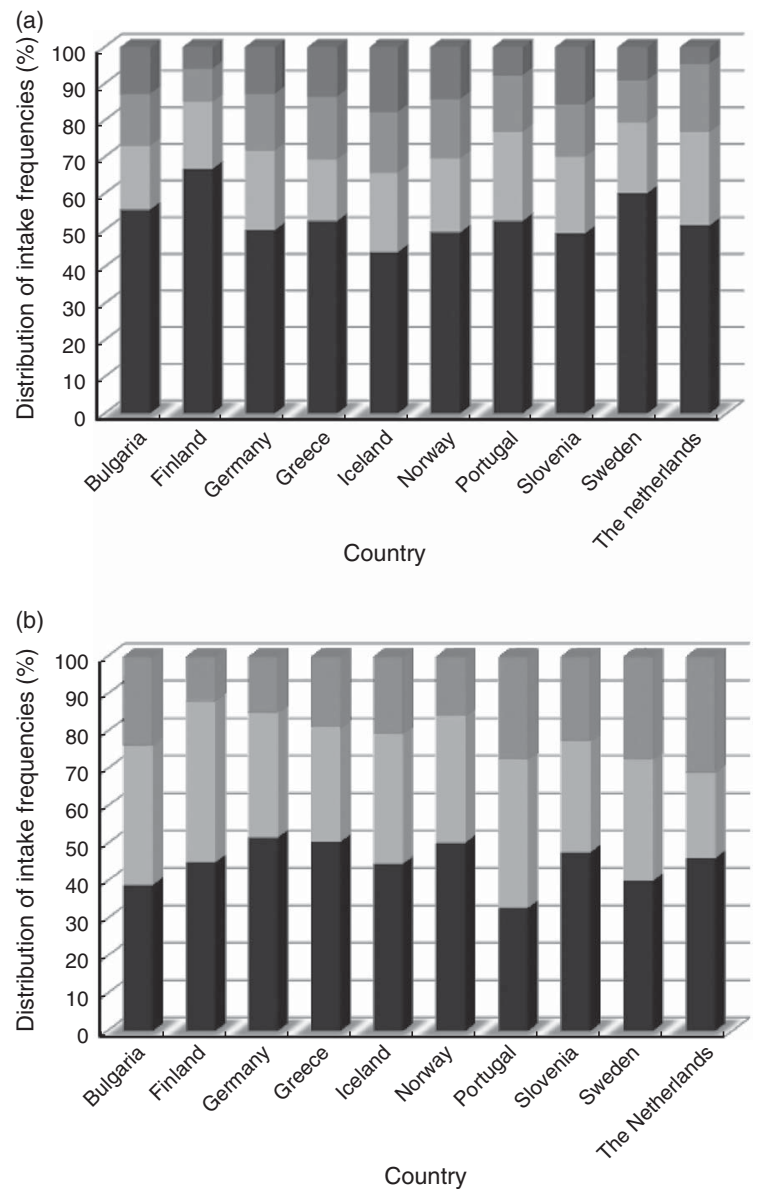

Fig. 2 Distribution (\%) of intake frequencies (times per day) of (a) fruits ( $\square,>2$ times/d;, 2 times/d;, 1 time/d; $\square,<1$ time/d) and (b) vegetables ( $\square, \geq 2$ times/d; $\square, 1$ time/d; $\square,<1$ time/d) per country (FFQ) among 11-year-old children ( $n$ 8158) from 236 schools across ten European countries participating in the PRO GREENS project, April-October 2009 
fruit once daily or more. On average $53.3 \%$ of the children reported not to eat fruit daily. Iceland was the country where the largest proportion of children (55.8\%) reported eating fruit at least once daily, in contrast to the results from the $24 \mathrm{~h}$ recall, where children in Iceland had the second lowest intake of fruit. The country where the largest proportion of children reported eating vegetables at least once daily was Finland (67.0\%), and the country where the smallest proportion of children reported eating vegetables at least once daily was Norway (48.2\%). On average, $44.9 \%$ of the children reported eating vegetables less than once daily.

\section{Discussion}

The main results showed that children in the investigated countries still do not meet the recommendations for F\&V consumption, with only $23.5 \%$ of the whole sample reaching the WHO recommendation of $400 \mathrm{~g} / \mathrm{d}$. More than half $(53.3 \%)$ of the children in the total survey reported not eating fruit daily, while the corresponding results for vegetables were slightly more promising according to the FFQ (44.9\%). There were relatively large variations in total F\&V intake between countries and also when looking at fruit and vegetable intakes separately, as well as consumption of different types and preparations of vegetables between countries. The mean and median intakes were low in all countries, especially the vegetable intakes. Boys had a lower intake of both fruit and vegetables in general, with the exception of some countries (Germany and Greece for fruit, Greece and Portugal for vegetables) where results showed a tendency of the opposite. The Pro Children study also revealed a gender difference with a lower F\&V intake in boys in the countries studied ${ }^{(10)}$. In Germany, the findings differ slightly from those of a population-wide consumption survey ${ }^{(32)}$, which found a mean daily F\&V intake of $230 \mathrm{~g}$ in boys and $259 \mathrm{~g}$ in girls aged 11 years. The mean gender difference of $10 \mathrm{~g} / \mathrm{d}$ might reflect regional, ethnic and economic aspects of the study population in PRO GREENS.

In most F\&V recommendations, fruit juice is included, either unlimited or up to a certain amount ${ }^{(10)}$. The evidence for the benefits of fruit juice is, however, much less clear than for F\&V. F\&V are higher in fibre and less concentrated in sugar and there is even some evidence indicating an increased risk of type 2 diabetes with a high consumption of juice in adults ${ }^{(33)}$. When comparing the intakes of the group of children participating in the current study with the recommendations, one needs to keep in mind that the intakes most likely would be slightly higher if intake of fruit juice were included. As described in the Methods section, an additional reason why we did not include fruit juice in the calculations was that it was shown in focus group interviews that children had problems distinguishing between real fruit juice and other fruit-based or -flavoured drinks, like lemonade and sodas $^{(31)}$. However, national intake recommendations are in most cases higher than the WHO population goal of $\geq 400 \mathrm{~g} / \mathrm{d}$ and the WHO recommendation does not specify whether fruit juice should be included.

The vegetable intake was lower than the fruit intake in all countries. Children often tend to like fruit better than vegetables and may find fruit more accessible as a snack. The low vegetable intake may also be due to a low availability and/or accessibility at home or in school ${ }^{(10,34)}$. The types of vegetables consumed and how they were prepared and served varied significantly between the countries included, which was also seen in the Pro Children study ${ }^{(10)}$. In the Nordic countries (Finland, Iceland, Norway and Sweden) the most commonly eaten types of vegetables were raw vegetables. Especially in Portugal but also in Bulgaria and Slovenia to a certain extent, soup vegetables were more commonly eaten than in the other countries. The type and preparation method of vegetables affects several factors, such as the matrix of the vegetable, which may hinder uptake; but also heat, exposure to oxygen and/or light, cutting, diffusion, homogenization and fat used during processing can change the nutrient level and/or bioavailability in cooked $v$. raw vegetables ${ }^{(35-37)}$. The bioavailability of carotenoids is greatly increased by cooking or homogenization and the total antioxidant capacity of vegetables increases, probably due to matrix softening and increased possibilities to extract and absorb the compounds of antioxidant nature $^{(35,36)}$. Ascorbic acid and other water-soluble vitamins and vitamin-like components in vegetables do, however, diffuse into cooking liquids and some are destroyed by heat ${ }^{(37)}$. The choice of cooked or raw vegetables, which the current study shows to differ between countries, most likely depends on cultural factors and availability at home or at school lunch and not necessarily or primarily the preference of the child. Since vegetable intake seems to be the most difficult to increase in a number of intervention studies ${ }^{(28)}$, knowledge regarding the most common type of vegetables and the way they are served might provide useful information to tailor future interventions promoting vegetable intake.

The intake levels observed in the present survey are considerably higher than intakes measured in the previous European survey, Pro Children ${ }^{(10)}$ in 2003. The mean intakes of total F\&V were between 220 and $345 \mathrm{~g} / \mathrm{d}$ in the present study (231-345 g/d in the Pro Children countries also participating in PRO GREENS and $220-320 \mathrm{~g} / \mathrm{d}$ in the new countries in PRO GREENS) and in the Pro Children survey intakes were $143-265 \mathrm{~g} / \mathrm{d}(143-264 \mathrm{~g} / \mathrm{d}$ in the five countries also participating in the current study). These results are however not directly comparable, since different sampling methods were used in the two studies. In Pro Children all countries except for two (Austria and Belgium) had nationally representative samples. Intake levels especially in Norway and especially for fruit seem to 
have increased substantially (in Pro Children $149 \mathrm{~g} / \mathrm{d}$, in the present study $240 \mathrm{~g} / \mathrm{d}$ ). The fact that the sampling method in Norway was different for the two studies may have affected the results, but it is also likely that the several promotional programmes to increase $\mathrm{F} \& \mathrm{~V}$ intake that have been run in Norway in the period 2003 to $2009^{(27)}$ have had an effect. The fact that children's F\&V intake was based on child reports, which may evoke socially desirable answers, might result in over-reporting, especially in a country where campaigns have been most widespread and intense. In a study by Fischer et al. mediation analyses showed that knowledge of the recommendations, parental demand and parental facilitation explained most of this difference in fruit intake in the Netherlands between 2003 and 2009. This suggests that school programmes and/or media activities were able to raise awareness among both children and parents ${ }^{(38)}$.

Earlier national dietary surveys including F\&V intake in the participating countries were generally in line with the results from the current study ${ }^{(25,26,39-45)}$. Results from the FFQ in the current study also showed a similar pattern for fruit intake as the latest Health Behaviour in School-Aged Children survey (HBSC) ${ }^{(46)}$. Among the PRO GREENS countries included in the HBSC study, Finland reported the lowest percentage of children eating fruit at least once daily, while Iceland, Norway, Portugal and Slovenia were among the countries with the highest percentage of children reporting eating fruit once daily or more according to the HBSC, results in agreement with our data.

The presence or absence of a school meal in some of the countries may partially explain differences between countries in the present study ${ }^{(47)}$. For example, Germany, the Netherlands and Norway have no school meals. Instead, children bring a packed lunch to school (the Netherlands, Norway) or eat lunch after school at home (Germany). It is likely that the average packed lunch does not always contain vegetables. The amount of vegetables eaten in school may also vary drastically between schools and countries where school meals are served depending on school meal quality. In Sweden, where the vegetable intake is the highest among the countries in the present study, the school lunch and its salad bar play an important role. Finland offers a similar school lunch to Sweden, which could contribute to why Finnish children consumed more vegetables than the average sample, while the fruit consumption was the lowest of all participating countries. Further studies are needed to confirm the factors behind the differences in consumption between countries. In Norway, a lot of effort has been made to provide fruit in school and to promote fruit breaks in class, which could explain the high fruit intake in the Norwegian sample.

When interpreting the current findings, some limitations need to be taken into account. The sample in the study was not nationally population representative, with the exception of Slovenia and the Netherlands. Therefore it is not possible to draw a general conclusion regarding the overall situation in the eight countries with regional samples. Since participation in the study was done on a voluntary basis, schools actually participating were likely more inclined to be aware of and interested in healthy eating. This may have positively affected the consumption or the responses. Some countries (especially Norway, but also Iceland, Sweden and the Netherlands) had low response rates among schools, which could have introduced a selection bias. If this was the case, the true representative intake levels for the selected region may likely be lower than reported here. This might partially explain why Norway, in contrast to the results in the Pro Children study, had the highest fruit intake as well as total F\&V intake in the current study, since it might be the case that only the schools that had a larger interest in this topic, and subsequently a higher intake, chose to participate.

Most countries performed the survey during the period April-June in 2009. Due to difficulties in recruiting schools and delays in obtaining parental consent, the time of assessment was delayed in Norway, Sweden and Iceland to September-October. The seasonal effect could have had an impact on intake levels in these countries compared with the others, since locally grown F\&V are more available during the autumn in Scandinavia.

The main limitation of the assessment method was that intakes were recorded for one weekday only in the precoded $24 \mathrm{~h}$ recall instrument and that the results therefore did not reflect usual individual intake. However, on a group level, this method is more reliable and can be considered to reflect average intake of the group. The FFQ should to some extent reflect usual intake better, but on comparison, the ranking of countries based on actual intake ( $24 \mathrm{~h}$ recall) differed quite substantially from the ranking of usual intake (FFQ). The differences in ranking of countries for actual intake compared with usual intake could be due to the problem with portion size estimation, both in the $24 \mathrm{~h}$ recall but also that frequencies of intakes did not take portion sizes into account.

Our study clearly showed that interventions are needed to promote $\mathrm{F} \& \mathrm{~V}$ consumption in this age group. From earlier studies such as the Pro Children study ${ }^{(24,30)}$ we know that these interventions should target the most important and modifiable determinants of F\&V intake. Home and school availability is a very important facilitating determinant of F\&V intake and the subsequent PRO GREENS intervention will address this. Furthermore, our study meant that the Pro Children tool was translated into another four languages (German, Bulgarian, Greek and Slovenian), a questionnaire that can be used for free over Europe $^{(48)}$. PRO GREENS also adds knowledge about the current intake levels of fruit and of vegetables among samples of children in ten European countries measured with a validated questionnaire especially designed to assess F\&V intake, and additionally new information about intake in five countries not previously included in a similar study. 


\section{Conclusions}

The present cross-sectional survey shows that the mean consumption levels of F\&V in this sample of 11-year-old children were not reaching the WHO population goal. A large number of children stated a frequency of less than once daily for fruit intake and vegetable intake. Vegetable intake was even lower than the fruit intake, which shows the importance of focusing promotional efforts in this field. Despite not reaching population goals for intake of $F \& V$, results from some countries show positive and promising indications, especially in Norway where it seems that the many promotional programmes over the past decade might have had an effect on fruit intake. In order to draw any definite conclusions nationally representative surveys need to be conducted.

The future analyses of the intervention study based on these data will provide more information about the potential of strategies for $\mathrm{F} \& \mathrm{~V}$ promotion among children in Europe.

\section{Acknowledgements}

Acknowledgements: The authors would like to thank all the schools that participated and the staff at each centre who contributed to the data collection in this survey. Financial support: The PRO GREENS project was made possible by financial support through the Programme of Community Action in the Field of Public Health 2003-2008 of the European Commission. The study does not necessarily reflect the Commission's views and in no way anticipates its future policy in this area. Additional support was provided by The Research Fund of the University of Iceland and the Ax:son Johnson Foundation, Sweden. The above-mentioned funders had no role in the design, analysis or writing of this article. Conflict of interest: None. Authorship: C.L. drafted the manuscript and performed the data analyses with support from some of the co-authors. All authors contributed to the collection of data and editing of the manuscript. A.G.K. was responsible for the handling and cleaning of the merged data and double-checked the descriptive analyses. S.J.t.V., T.I.H. and E.P. contributed with support in the statistical analyses of differences in intakes. Ethics of human subject participation: Ethical approvals for this study have been obtained from: the Regional Ethical Review Board, Stockholm, Sweden; Norwegian Social Science Data Services, Bergen, Norway; MedischEtischeToetsingscommissie, VU Medical Center, Amsterdam, the Netherlands; the Ethics Committee at the Department of Public Health, Faculty of Medicine, University of Helsinki, Helsinki, Finland; the National Bioethics Committee, Reykjavik, Iceland; the Ethics Committee of Justus-Liebig University in Giessen, Germany; the Ministry of Education and headmasters of School Julio Saul Dias and School Freijoão de Vila do Conde, Portugal; the
National Medical Ethics Committee of the Republic of Slovenia, Ljubljana, Slovenia; the Ministry of Education, Lifelong Learning and Religious Affairs, Greece; and the Commission of Medical Ethics at the National Centre of Public Health Protection, Sofia, Bulgaria.

\section{References}

1. World Health Organization (2004) Global Strategy on Diet, Physical Activity and Health. Geneva: WHO.

2. World Health Organization (2009) Global Health Risks: Mortality and Burden of Disease Attributable to Selected Major Risks. Geneva: WHO.

3. World Cancer Research Fund/American Institute for Cancer Research (2007) Food, Nutrition, Physical Activity and the Prevention of Cancer: A Global Perspective. Washington DC: AICR.

4. He FJ, Nowson CA, Lucas M et al. (2007) Increased consumption of fruit and vegetables is related to a reduced risk of coronary heart disease: meta-analysis of cohort studies. J Hum Hypertens 21, 717-728.

5. He FJ, Nowson CA \& MacGregor GA (2006) Fruit and vegetable consumption and stroke: meta-analysis of cohort studies. Lancet 367, 320-326.

6. Carter P, Gray LJ, Troughton J et al. (2010) Fruit and vegetable intake and incidence of type 2 diabetes mellitus: systematic review and meta-analysis. BMJ 341, c4229.

7. Key TJ, Schatzkin A, Willett WC et al. (2004) Diet, nutrition and the prevention of cancer. Public Health Nutr 7, 187-200.

8. Nordic Council of Ministers (2004) Nordic Nutrition Recommendations 2004: Integrating Nutrition and Physical Activity, 4th ed. Nord 2004:13. Copenhagen: Nordic Council of Ministers.

9. World Health Organization (2003) Diet, Nutrition and the Prevention of Chronic Diseases. Joint WHO/FAO Expert Consultation. WHO Technical Report Series no. 916. Geneva: WHO.

10. Yngve A, Wolf A, Poortvliet E et al. (2005) Fruit and vegetable intake in a sample of 11-year-old children in 9 European countries: the Pro Children Cross-sectional Survey. Ann Nutr Metab 49, 236-245.

11. Livsmedelsverket (2003) Ett halvt kilo om dagen!. Uppsala: Livsmedelsverket.

12. Voedingscentrum (1998) Zo eet Nederland Den Haag: Voedingscentrum.

13. Blomhoff R, Lande B \& Ose T (1996) Recommendations for Increased Intake of Fruit and Vegetables. Oslo: National Nutrition Council.

14. Steingraimsdottir L, Thorgeirsdottir H \& Olafsdottir A (2003) The Diet of Icelanders. Dietary Survey of the Icelandic Nutrition Council 2002: Main Findings. Reykjavik: Icelandic Nutrition Council

15. Statens näringsdelegation (2005) Finska näringsrekommendationer. Helsingfors: Statens näringsdelegation.

16. Faculdade de Ciencias da Nutricao e Alimentacao da Universidade do Porto \& Instituto do Consumidor (2003) $A$ nova roda dos alimentor. Uma guia para escolha alimentar diaria! Coma bem, viva melhor. Porto: Universidade do Porto.

17. Deutsche Gesellschaft für Ernährung (2008) Ernährungsbericht. Bonn: DGE.

18. Petrova S, Angelova K, Duleva V et al. (2008) Food Based Dietary Guidelines for Schoolchildren aged 7-19 Years in Bulgaria. Sofia: Dunav Press.

19. Ministry of Health and Welfare, Supreme Scientific Health Council (1999) Dietary guidelines for adults in Greece. Arch Hellenic Med 16, 516-524. 
20. Ministrstvo za zdravje Republike Slovenije (2004) $D-A-C H$ Referenčne vrednosti za vnos hranil. Delovna skupina za pripravo 'Referenčnib vrednosti za vnos hranil'. Nemško prehransko društvo, Avstrijsko prehransko društvo, Švicarsko društvo za raziskovanje prehrane, Švicarsko združenje za prehrano. Ljubljana: Ministrstvo za zdravje Republike Slovenije.

21. Lake AA, Adamson AJ, Craigie AM et al. (2009) Tracking of dietary intake and factors associated with dietary change from early adolescence to adulthood: the ASH30 study. Obes Facts 2, 157-165.

22. Lien N, Lytle LA \& Klepp KI (2001) Stability in consumption of fruit, vegetables, and sugary foods in a cohort from age 14 to age 21. Prev Med 33, 217-226.

23. te Velde SJ, Twisk JW \& Brug J (2007) Tracking of fruit and vegetable consumption from adolescence into adulthood and its longitudinal association with overweight. Br J Nutr 98, 431-438.

24. te Velde SJ, Brug J, Wind M et al. (2008) Effects of a comprehensive fruit- and vegetable-promoting school-based intervention in three European countries: the Pro Children Study. Br J Nutr 99, 893-903.

25. Reinaerts E, Crutzen R, Candel M et al. (2008) Increasing fruit and vegetable intake among children: comparing longterm effects of a free distribution and a multicomponent program. Health Educ Res 23, 987-996.

26. Tak NI, te Velde SJ \& Brug J (2009) Long-term effects of the Dutch Schoolgruiten Project - promoting fruit and vegetable consumption among primary-school children. Public Health Nutr 12, 1213-1223.

27. Bere E, Hilsen M \& Klepp KI (2010) Effect of the nationwide free school fruit scheme in Norway. Br J Nutr 104, 589-594.

28. Evans CE, Christian MS, Cleghorn CL et al. (2012) Systematic review and meta-analysis of school-based interventions to improve daily fruit and vegetable intake in children aged 5 to 12 y. Am J Clin Nutr 96, 889-901.

29. Haraldsdottir J, Thorsdottir I, de Almeida MD et al. (2005) Validity and reproducibility of a precoded questionnaire to assess fruit and vegetable intake in European 11- to 12-yearold schoolchildren. Ann Nutr Metab 49, 221-227.

30. Klepp KI, Perez-Rodrigo C, De Bourdeaudhuij I et al. (2005) Promoting fruit and vegetable consumption among European schoolchildren: rationale, conceptualization and design of the Pro Children project. Ann Nutr Metab 49, 212-220.

31. Wind M, Bobelijn K, De Bourdeaudhuij I et al. (2005) A qualitative exploration of determinants of fruit and vegetable intake among 10- and 11-year-old schoolchildren in the low countries. Ann Nutr Metab 49, 228-235.

32. Mensink GB, Bauch A, Vohmann C et al. (2007) EsKiMo the nutrition module in the German Health Interview and Examination Survey for Children and Adolescents (KiGGS). Bundesgesundheitsblatt Gesundheitsforschung Gesundbeitsschutz 50, 902-908.

33. Muraki I, Imamura F, Manson JE et al. (2013) Fruit consumption and risk of type 2 diabetes: results from three prospective longitudinal cohort studies. BMJ 347, f5001.
34. Yngve A (2005) Intake of fruit and vegetables in European children and their mothers, folate intake in Swedish children and health indicators: overweight, plasma homocysteine levels and school performance. PhD Thesis, Karolinska Institutet.

35. van Het Hof KH, West CE, Weststrate JA et al. (2000) Dietary factors that affect the bioavailability of carotenoids. J Nutr 130, 503-506.

36. Miglio C, Chiavaro E, Visconti A et al. (2008) Effects of different cooking methods on nutritional and physicochemical characteristics of selected vegetables. J Agric Food Chem 56, 139-147.

37. Delchier N, Ringling C, Le Grandois J et al. (2013) Effects of industrial processing on folate content in green vegetables. Food Chem 139, 815-824.

38. Fischer C, Brug J, Tak NI et al. (2011) Differences in fruit and vegetable intake and their determinants among 11-yearold schoolchildren between 2003 and 2009. Int J Behav Nutr Phys Act 8, 141.

39. Enghardt Barbieri H, Pearson M \& Becker W (2006) Riksmaten - barn 2003: livsmedels-och näringsintag bland barn i Sverige. Uppsala: Livsmedelsverket.

40. Hoppu U, Lehtisalo J, Tapanainen H et al. (2010) Dietary habits and nutrient intake of Finnish adolescents. Public Health Nutr 13, 965-972.

41. Ute A, Sichert-Hellert W \& Kersting M (2002) Fifteen-year time trends in energy and macronutrient intake in German children and adolescents: results of the DONALD study. BrJ Nutr 87, 595-604.

42. Talvia S, Rasanen L, Lagstrom H et al. (2006) Longitudinal trends in consumption of vegetables and fruit in Finnish children in an atherosclerosis prevention study (STRIP). Eur J Clin Nutr 60, 172-180.

43. Mensink GBM, Kleiser A \& Richter A (2007) Food consumption of children and adolescents in Germany. Results of the German Health Interview and Examination Survey for Children and Adolescents (KiGGS). Bundesgesundheitsblatt Gesundheitsforschung Gesundheitsschutz 50, 609-623.

44. Linardakis M, Bertsias G, Sarri K et al. (2008) Metabolic syndrome in children and adolescents in Crete, Greece, and association with dietary quality and physical fitness. J Public Health 16, 421-428.

45. Baykova D, Petrova S, Markov P et al. (2009) Food consumption of children aged 10-14 years (National monitoring 2004). Hranitelno-vkusova promishlenost 2, 45-49 (in Bulgarian).

46. Currie C, Gabhainn SN, Godeau E et al. (2008) Inequalities in Young People's Health. Health Behaviour in School-Aged Children. International Report from the 2005/2006 Survey. Health Policy for Children and Adolescents no. 5. Copenhagen: WHO Regional Office for Europe.

47. Stevens L, Nicholas J, Wood L et al. (2013) School lunches $v$. packed lunches: a comparison of secondary schools in England following the introduction of compulsory school food standards. Public Health Nutr 16, 1037-1042.

48. PRO GREENS project (2013) Assessment tools. http://www. progreens.org/tools.html (accessed February 2013). 